\title{
Dietary diversity and related factors among lactating women visiting public health facilities in Aksum town, Tigray, Northern Ethiopia
}

Negassie Berhe Weldehaweria ${ }^{1 *}$ (D, Kebede Haile Misgina ${ }^{1}$, Meresa Gebremedhin Weldu, Yosef Sibhatu Gebregiorgis ${ }^{1}$, Berhane Hailu Gebrezgi², Shewit Weldu Zewdie ${ }^{3}$, Helen Aregawi Ngusse, Higus Guesh Gebrewa ${ }^{3}$ and Wubrst Alemu ${ }^{3}$

\begin{abstract}
Background: Dietary diversity is a proxy indicator of maternal nutrient adequacy. However, little is documented on dietary diversity among lactating mothers. Therefore, this study assessed diet diversity and associated factors among lactating mothers visiting public health facilities in Aksum town, Tigray, Northern Ethiopia.

Methods: An institution based cross-sectional study was conducted on 346 randomly selected lactating women visiting public health facilities of Aksum town in June 2015. Dietary diversity was assessed using $24 \mathrm{~h}$ dietary recall method. A mean dietary diversity score (DDS) was computed of nine food groups. Food insecurity access was measured using 9 items Household Food Insecurity Access Scale (HFIAS). Data were entered and analyzed using SPSS version 20.

Results: More than a quarter (27.2 \%) of the lactating mothers was from food insecure households. The mean DDS was 3.4 and a total of $56.4 \%$ lactating mothers had low dietary diversity (less than mean DDS). Average monthly income, home gardening and source of drinking water were associated with low dietary diversity. Lactating mothers who had monthly income of less than $501 \mathrm{ETB}[\mathrm{AOR}=2.3,95 \% \mathrm{Cl}(1.2,4.6)]$ and 501 to 1500 $\mathrm{ETB}[\mathrm{AOR}=3.0,95 \% \mathrm{Cl}(1.4,6.3)]$ were more likely to have low dietary diversity than those who had monthly income above 1500 ETB. And those who did not practice home gardening were more likely to have low dietary diversity than their counterparts $[A O R=2.1,95 \% \mathrm{Cl}(1.01,4.2)]$. Regarding source of drinking water, mothers who reported protected well as a main source were more likely to have low dietary diversity compared to those who reported tap water as main source $[A O R=4.5,95 \% \mathrm{Cl}(1.1,18.2)]$.
\end{abstract}

Conclusions: Dietary diversity among lactating mothers was low. Factors like monthly income less than 501 ETB and 501 to 1500 ETB, not having home gardening, and source of drinking water from protected well were significantly associated with low dietary diversity. Attention should be paid to dietary diversity of lactating mothers to improve their nutritional status, and that of their children and their family.

Keywords: Lactating mothers, Dietary diversity, Tigray, Ethiopia

\footnotetext{
* Correspondence: negelsa5960@gmail.com

'Department of Public Health, College of Health Sciences, Aksum University,

P. O. Box: 1010, Aksum, Ethiopia

Full list of author information is available at the end of the article
} 


\section{Background}

Women at reproductive age, particularly those who live in low and middle income countries, are vulnerable to malnutrition for two major reasons. Physiological vulnerability which comes with childbearing is the first reason. Moreover, maternal nutrient needs increase during pregnancy and lactation, and when these needs are not met, women may suffer from malnutrition [1-5]. During lactation, the energy, protein, and other nutrients in breast milk come from a mother's diet or her own body stores. Lactating women who do not get enough energy and nutrients in their diets risk maternal depletion [3-6]. This exacerbates maternal malnutrition $[7,8]$. In addition, maternal deficiencies of nutrients can affect the quality of breast milk which can adversely affect the nutritional status of their child and eventually compromise the overall growth and development of the child $[3-5,9,10]$.

According to the United Nations Children's Fund (UNICEF) conceptual framework of malnutrition, the immediate causes of maternal malnutrition are inadequate dietary intake and diseases; while the underlying causes are inadequate access for food, inadequate care for women and insufficient health services and unhealthy environment [11]. These causes are recognized as stemming from wider contextual factors such as educational and socioeconomic status, ethnic and cultural beliefs, agricultural practices, national policies, and food insecurity [12].

One of the proxy indicators for measuring dietary adequacy among lactating mothers is dietary diversity which is defined as the number of different foods or food groups ( 9 food groups in this case) consumed over a given reference period [13-21]. The diets of lactating mothers reflect not only their own intake, but also the diets of their small children and families [22-25]. That is, maternal dietary diversity is also strongly linked to that of infants in the same household and to the average household nutrient adequacy. In short, lactating mothers with higher dietary diversity have children and family with higher dietary diversity [19, 22-25]. Hence, ensuring maternal dietary diversity to the acceptable level is very important in tackling malnutrition.

However, literatures evidenced that dietary diversity among lactating mothers is very low in Ethiopia. According to a study conducted in three countries; Vietnam, Bangladesh, and Ethiopia, dietary diversity was very low in nearly three fourth of lactating mothers in Ethiopia [26]. A number of factors could contribute to poor dietary diversity. Evidences show that many factors including maternal education, food security and socioeconomic status could act as barriers to diversified dietary use [26, 27]. Moreover, maternal knowledge [26], health status [26, 27] and season could influence dietary diversity $[16,27]$. These factors could vary from setting to setting. Therefore, information on dietary diversity and associated factors of lactating mothers are urgently needed for prioritizing, designing and initiating intervention programs aiming at improving maternal and child nutrition. However, little is documented on dietary diversity and the associated factors in the study area. Therefore, this study aims to assess dietary diversity and associated factors among lactating mothers in Aksum town, Tigray region, North Ethiopia.

\section{Methods}

\section{Study setting and population}

Health facility based cross-sectional design was employed to assess dietary diversity among lactating mothers in public health facilities of Aksum town. Aksum town is located in the Northern part of Ethiopia with an elevation of $2131 \mathrm{~m}(6991 \mathrm{ft})$ above sea level, with annual average temperature of $18.3^{\circ} \mathrm{C}$ and annual rain fall of $652 \mathrm{~mm}$. It is $1042 \mathrm{kms}$ far from Addis Ababa, the capital of Ethiopia and $270 \mathrm{kms}$ away from Mekelle (the capital city of Tigray regional state). Aksum is the ancient historical town which has an area of $3247 \mathrm{~km}^{2}$. Based on the town administrative office 2013 report, the total population is 59,300 (28,637 are males and 30,663 are females). Administratively, the town is divided in to 4 kebeles (the smallest administrative units). In Aksum town, there are 2 governmental health centers and 1 governmental general hospital. Lactating mothers who visit the public health facilities during the study period were considered as the study population. The inclusion criteria were being 15-49 years lactating mother and being resident of Aksum town for at least 6 months. Lactating mothers who were seriously ill and/or had difficulty to communicate were excluded. The data collection was undertaken in June, 2015.

\section{Sample size and sampling procedures}

The required sample size was determined using singlepopulation proportion formula with the following assumptions: $50 \%$ of proportion of lactating mothers who have below mean diet diversity score, $95 \%$ of confidence interval and $5 \%$ marginal error. The final sample size was 384. Respondents who fulfilled the inclusion criteria were selected using systematic random sampling technique. The interview was started by selecting a random start using lottery method. Then every $2^{\text {nd }}$ lactating woman visiting the public health facilities were interviewed. Eventually, a total of 346 lactating mothers were participated in this study.

\section{Data collection}

Data were collected by exit interview using structured and pre-tested questionnaire adapted from different literatures mainly Food and Agriculture Organization (FAO) Guidelines for measuring household and individual dietary diversity, 2011 [15] and Household food 
insecurity access scale (HFIAS) to measure food security [23]. The questionnaire had four main contents: sociodemographic characteristics; source of food, feeding practice and other individual related factors; dietary diversity, and food security related questions. The questionnaire was first prepared in English and then translated to Tigrigna and translated back to English to observe its consistency. Finally, the questionnaire was also pretested on $5 \%$ of the total sample size in Suhul general hospital found in Shire Endaselassie town of North Western zone of Tigray Regional state. Necessary modifications were made on the questionnaire based on the findings of the pretest.

Dietary diversity score (DDS) was collected and calculated as the sum of the number of different food groups consumed by the mother in the $24 \mathrm{~h}$ prior to the assessment. A total of nine food groups were considered in this study (i.e. starchy staples, dark green leafy vegetables, other vitamin A rich fruits and vegetables, other fruits and vegetables, fats and oils, meat and fish, eggs, legumes, nuts and seeds and milk and milk products [28]. Finally, respondents with $<3.4$ mean food groups consumed were considered as having lower dietary diversity whereas those with $\geq 3.4$ mean food groups consumed were considered as having moderate or high dietary diversity.

Food insecurity access was measured using items from the HFIAS [23, 29-31]. The HFIAS consists of 9 items specific to an experience of food insecurity occurring within the previous 4 weeks. Each respondent indicated whether he/she had encountered the following due to lack of food or money to buy food in the previous 1 month: (1) worried about running out of food, (2) lack of preferred food, (3) the respondent or another adult had limited access to a variety of foods due to a lack of resources (4) forced to eat un preferred food due to lack of resources, (5) eating smaller portions, (6) skipping meals, (7) the household ran out of food, (8) going to sleep hungry, and (9) going $24 \mathrm{~h}$ without food. Finally, individuals were classified as food secure if the individuals responded 'no' to all of the items and insecure if the individuals responded 'yes' to at least one of the 9 items included on the HFIAS tool.

Two public health officers, who were fluent in the local language (Tigrigna), participated in the data collection process. The data collection process was supervised by two senior Public Health professionals and the principal investigators. Both data collectors and supervisors were trained for 1 day about the contents of the questionnaire and on how to collect the data properly in order to minimize errors. The principal investigators and supervisors had made daily supervision during the whole data collection process. The questionnaire was reviewed and checked for completeness, accuracy and consistency by the supervisors and investigators daily and at the end of the whole data collection process.

\section{Operational definition \\ Diet diversity score}

Is the sum of food groups eaten in the previous $24 \mathrm{~h}$, serves as a proxy indicator of nutrient adequacy of an individual's diet. Low dietary diversity $(<3.4$ mean food groups consumed) and moderate or high dietary diversity ( $\geq 3.4$ mean food groups consumed). The diet was classified according to the 9 food groups recommended by the FAO [28].

\section{Food security}

Food insecurity access was measured using items from the HFIAS [23, 29-31]. The HFIAS consists of 9 items specific to an experience of food insecurity occurring within the previous 4 weeks. Each respondent indicated whether he/she had encountered the 9 items included in the HFIAS due to lack of food or money to buy food in the previous 1 month. Finally, individuals were classified as food secure if the individuals responded 'no' to all of the items and insecure if the individuals responded 'yes' to at least one of the 9 items included on the HFIAS tool.

\section{Data analysis}

After all the relevant data were collected, the data were coded on pre- arranged coding sheet by the investigators. Dietary intake was converted to 9 food groups to assess dietary diversity of the subjects. Data were entered, cleaned and then analyzed using SPSS version 20. Descriptive summaries using frequencies and proportions were used to present the study results. In this study, the dependent variable was dietary diversity coded 1 as lower dietary diversity and 0 as moderate or high dietary diversity. In the bivariate analysis, the independent variables with a $P$-value less than 0.2 with the dependent variable were fitted in to a multivariate logistic regression model to identify their independent effect on dietary diversity. Independent variables included in the multivariate analysis include educational status, occupation, residential address, monthly income, source of drinking water, availability of latrine, home gardening, history of illness, duration of menstruation (in days) and daily eating pattern in the previous 7 days. The association between the dependent and the independent variables was measured using odds ratio (OR) with $95 \%$ Confidence Interval (C.I). Those variables with $p$-value of less than 0.05 in the multivariate analysis were considered as significant.

\section{Results}

\section{Characteristics of respondents}

Table 1 shows characteristics of respondents. Three hundred forty six lactating women were included in this 
Table 1 Characteristics of lactating mothers $(n=346)$ visiting public health facilities in Aksum, Tigray, Northern Ethiopia, June 2015

\begin{tabular}{|c|c|}
\hline Characteristics & Number (percent) \\
\hline \multicolumn{2}{|l|}{ Age } \\
\hline $15-30$ & $240(69.4)$ \\
\hline $31-40$ & $86(24.9)$ \\
\hline$>40$ & $20(5.8)$ \\
\hline \multicolumn{2}{|l|}{ Residential address } \\
\hline Urban & $280(80.9)$ \\
\hline Rural & $66(19.1)$ \\
\hline \multicolumn{2}{|l|}{ Religion } \\
\hline Orthodox & $306(88.4)$ \\
\hline Muslim & 40 (11.6) \\
\hline \multicolumn{2}{|l|}{ Marital status } \\
\hline Single & $18(5.2)$ \\
\hline Married & $299(86)$ \\
\hline Divorced & $22(6.4)$ \\
\hline Widowed & $7(2)$ \\
\hline \multicolumn{2}{|l|}{ Educational status } \\
\hline No formal education & $57(16.5)$ \\
\hline Elementary (1-8) & $130(37.6)$ \\
\hline Secondary (9-12) & $113(32.6)$ \\
\hline $12+$ & $46(13.3)$ \\
\hline \multicolumn{2}{|l|}{ Occupational status } \\
\hline Unemployed & $66(19.1)$ \\
\hline House wife & $162(46.8)$ \\
\hline Daily laborer & $34(9.8)$ \\
\hline Private business $^{\mathrm{a}}$ & $84(24.3)$ \\
\hline \multicolumn{2}{|l|}{ Family size } \\
\hline $1-3$ & $25(7.2)$ \\
\hline $4-6$ & $250(72.3)$ \\
\hline$>6$ & $71(20.5)$ \\
\hline \multicolumn{2}{|l|}{ Source of drinking water } \\
\hline Tap water & $276(79.8)$ \\
\hline Pumping water & $53(15.3)$ \\
\hline Protected well & $17(4.9)$ \\
\hline \multicolumn{2}{|l|}{ Latrine availability } \\
\hline Yes & $284(82.1)$ \\
\hline No & $62(17.9)$ \\
\hline \multicolumn{2}{|l|}{ Average monthly income } \\
\hline$<501 \mathrm{ETB}^{\mathrm{b}}$ & $196(56.6)$ \\
\hline 501-1500 ETB & 99 (28.6) \\
\hline$>1500$ ETB & $51(14.8)$ \\
\hline \multicolumn{2}{|c|}{ History of illness in the previous 2 weeks } \\
\hline Yes & $53(15.3)$ \\
\hline No & $293(86.7)$ \\
\hline
\end{tabular}

Table 1 Characteristics of lactating mothers $(n=346)$ visiting public health facilities in Aksum, Tigray, Northern Ethiopia, June 2015 (Continued)

\begin{tabular}{ll}
\hline Age at first menstruation (years) & \\
$<13$ & $12(3.5)$ \\
$13-16$ & $286(82.7)$ \\
$>16$ & $48(13.9)$ \\
Duration of menstruation (days) & \\
$<4$ & $49(14.2)$ \\
$4-6$ & $270(78)$ \\
$>6$ & $27(7.8)$ \\
\hline
\end{tabular}

atrading, weaving, small local alcohol selling business

${ }^{\mathrm{b}} \mathrm{ETB}=$ Ethiopian birr

'Duration of menstruation refers to the usual duration of menstruation

study yielding a response rate of $90.1 \%$. The non- response rate was basically due to refusal to participate in the study and the lesser flow of mothers especially from rural areas to the health facilities because of increased summer activities by the farmers. More than two-thirds of the respondents $(69.4 \%)$ were in the age group of $15-30$ years and the mean age of the respondents was $29.8( \pm 6.1)$ years. Sixty six $(19.1 \%)$ of the respondents were rural dwellers. The majority of the respondents were Orthodox Christian (88.4\%) whilst the others were Muslims. Two hundred ninety nine $(95.7 \%)$ of the lactating mothers were married and 299 (86 \%) were Tigray. Almost half of the women $(46.0 \%)$ attended at least high school. Fifty seven $(16.5 \%)$ of the lactating mothers in this study had no formal education. One hundred sixty two $(46.8 \%)$ of lactating women were house wives. Regarding the family size of the lactating mothers participated in the study, 321 (92.8\%) of them reported that their family size was four and above. Concerning the source of drinking water for members of household, 276 (79.8\%) mothers reported tap water as their source of drinking water. Sixty two (17.9 \%) reported that they had no toilet facility in their home. More than half $(56.6 \%)$ of the lactating mothers had monthly income of less than 501 ETB. Among the total lactating mothers included in this study, 53 (15.3\%) reported history of illness in the previous 2 weeks. Most of the respondents $(78.0 \%)$ reported that their usual duration of menstruation was 4-6 days.

\section{Source of food and feeding practices}

Table 2 depicts source of food and feeding practices of the respondents. About two-thirds of lactating women $(60.7 \%)$ reported less than three meals per day during the previous 7 days. Only $11.8 \%$ reported having a garden at home. Pertaining to the main source of food for the household members, 143 (42.3\%) mothers reported 
Table 2 Source of food and feeding practice among lactating mothers $(n=346)$ visiting public health facilities in Aksum, Tigray, Northern Ethiopia, June 2015

\begin{tabular}{ll}
\hline Characteristics & $\begin{array}{c}\text { Number } \\
\text { (percent) }\end{array}$ \\
\hline Main source of food for household (current) & $143(41.3)$ \\
Own production & $164(47.4)$ \\
Purchasing & $27(7.8)$ \\
Food aid/relief & $12(3.5)$ \\
Other source & \\
Practicing home gardening & $41(11.8)$ \\
Yes & $305(88.2)$ \\
No & $136(39.3)$ \\
Daily eating pattern in the previous 7 days & $157(45.4)$ \\
Three meals \&/or above & $53(15.3)$ \\
Two meals \& eating between meals & \\
Two meals only or below & $205(59.2)$ \\
Frequency of fruit consumption in the previous 24 h & $107(30.9)$ \\
Not consumed at all & $34(9.8)$ \\
1-2 times & \\
Three times \& above & $183(52.9)$ \\
Frequency of vegetable consumption in the previous $24 \mathrm{~h}$ & $115(33.2)$ \\
Not consumed at all & $48(13.9)$ \\
1-2 times & $55(15.9)$ \\
Three times \& above & $291(84.1)$ \\
Yes & \\
No & \\
\hline
\end{tabular}

that their main source of food was household's own production. Regarding the frequency of fruit and vegetables consumption in previous $24 \mathrm{~h}$, more than half (59.2\%) and 183 (52.9\%) lactating mothers reported that they did not consume fruits and vegetables respectively. Among the lactating mothers, 55 (15.9\%) reported alcohol consumption during the previous 7 days.

\section{Dietary diversity characteristics}

Table 3 shows dietary diversity characteristics of the lactating mothers. The mean dietary diversity score among the lactating mothers was 3.4. Among the total lactating mothers, $56.4 \%$ (95\% CI: 50.6, 61.6) had low dietary diversity (dietary diversity score less than 3.4 ) and $43.6 \%$ (95 \% CI: 38.4, 49.4) of them had moderate or high dietary diversity (dietary diversity score greater or equal to 3.4 ) in the previous $24 \mathrm{~h}$. Regarding the food groups consumed by the lactating mothers in the previous $24 \mathrm{~h}$, nearly all women (99.4\%) consumed starchy staples and more than two-thirds (69.1\%) consumed legumes, nuts and seeds.
Table 3 Dietary diversity frequency of lactating mothers $(n=346)$ visiting public health facilities in Aksum, Tigray, Northern Ethiopia, June 2015

\begin{tabular}{ll}
\hline Food group consumption in previous $24 \mathrm{~h}$ & Number (percent) \\
\hline Starchy staples & $344(99.4)$ \\
Dark green leafy vegetables & $65(18.8)$ \\
Other vitamin A rich fruits and vegetables & $85(24.6)$ \\
Other fruits and vegetables & $145(41.9)$ \\
Fats and oils & $123(35.5)$ \\
Meat and fish & $59(17.1)$ \\
Eggs & $63(18.2)$ \\
Legumes, nuts and seeds & $239(69.1)$ \\
Milk and milk products & $43(12.4)$ \\
Women dietary diversity $\quad$ Low & $195(56.4)$ \\
& Moderate or high \\
\hline
\end{tabular}

\section{Food security characteristics}

Table 4 indicates food security characteristics of the lactating mothers. From the nine HFIAS items; lack of preferred food (12.1\%), worried about running out of food (11.8\%) and the respondent or another adult had limited access to a variety of foods due to a lack of resources (11\%) were the most frequently reported concerns about food insecurity. Overall, more than one fourth (27.2 \%) of the lactating mothers were food insecure.

\section{Factors associated with dietary diversity}

Table 5 shows bivariate and multivariate analysis of factors associated with dietary diversity of lactating mothers. In the bivariate level analysis, elementary education, being unemployed, monthly income of less than 501 ETB and

Table 4 HFIAS items of lactating mothers ( $n=346)$ visiting public health facilities in Aksum, Tigray, Northern Ethiopia, June 2015

\begin{tabular}{ll}
\hline HFIAS 9 items & $\begin{array}{l}\text { Number } \\
\text { (percent) }\end{array}$ \\
\hline Worried about running out of food & $41(11.8)$ \\
Lack of preferred food & $42(12.1)$ \\
The respondent or another adult had limited access to & $38(11.0)$ \\
$\begin{array}{l}\text { a variety of foods due to a lack of resources } \\
\text { Forced to eat un preferred food due to lack of resources }\end{array}$ & $25(7.2)$ \\
Eating smaller portions & $32(9.2)$ \\
Skipping meals & $21(6.1)$ \\
The household ran out of food & $19(5.5)$ \\
Going to sleep hungry & $11(3.2)$ \\
Going $24 \mathrm{~h}$ without food & $4(1.2)$ \\
Food security status ${ }^{\mathrm{a}}$ & $252(72.8)$ \\
& $94(27.2)$ \\
\hline
\end{tabular}

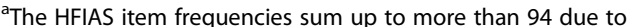
multiple response 
Table 5 Bivariate and multivariate associations of factors with dietary diversity among lactating mothers visiting public health facilities in Aksum, Tigray, Northern Ethiopia, June 2015

\begin{tabular}{|c|c|c|c|c|}
\hline \multirow[t]{3}{*}{ Characteristic } & \multicolumn{2}{|c|}{ Dietary diversity } & \multirow{3}{*}{$\begin{array}{l}\text { COR } \\
(95 \% \mathrm{Cl})\end{array}$} & \multirow{3}{*}{$\begin{array}{l}\text { AOR } \\
(95 \% \mathrm{Cl})^{\mathrm{b}}\end{array}$} \\
\hline & Low & Moderate or high & & \\
\hline & $n(\%)$ & $n(\%)$ & & \\
\hline \multicolumn{5}{|l|}{ Educational status } \\
\hline No formal education & $27(17.9)$ & $30(15.4)$ & $1.2(0.6-2.6)$ & $0.8(0.3-2.1)$ \\
\hline Elementary (1-8) & $46(30.5)$ & $84(43.1)$ & $2(1.01-3.9)$ & $1.4(0.6-3.5)$ \\
\hline Secondary (9-12) & $54(35.8)$ & $59(30.3)$ & $1.2(0.6-2.4)$ & $0.9(0.4-2.1)$ \\
\hline $12+$ & $24(15.9)$ & $22(11.3)$ & 1 & 1 \\
\hline \multicolumn{5}{|l|}{ Occupation } \\
\hline Unemployed & $22(14.6)$ & $44(22.6)$ & $2.3(1.2-4.5)$ & $2.2(1.0-4.7)$ \\
\hline House wife & $71(47)$ & $91(46.7)$ & $1.5(0.9-2.5)$ & $1.0(0.5-2.2)$ \\
\hline Daily laborer & $13(8.6)$ & $21(10.8)$ & $1.9(0.8-4.2)$ & $1.0(0.3-2.9)$ \\
\hline Private business & $45(29.8)$ & $39(20)$ & 1 & 1 \\
\hline \multicolumn{5}{|l|}{ Residential address } \\
\hline Urban & $126(83.4)$ & $154(79)$ & 1 & 1 \\
\hline Rural & $25(16.6)$ & $41(21)$ & $1.3(0.8-2.3)$ & $0.9(0.4-1.8)$ \\
\hline \multicolumn{5}{|l|}{ Average monthly income } \\
\hline$\leq 500 \mathrm{ETB}$ & $81(53.6)$ & $115(59)$ & $2.6(1.4-4.9)$ & $2.3(1.2-4.6)^{a}$ \\
\hline 501-1500 ETB & $37(24.5)$ & $62(31.8)$ & $3.1(1.5-6.2)$ & $3.0(1.4-6.3)^{\mathrm{a}}$ \\
\hline$>1500$ ETB & $33(21.9)$ & $18(9.2)$ & 1 & 1 \\
\hline \multicolumn{5}{|l|}{ Source of drinking water } \\
\hline Tap water & $129(85.4)$ & $147(75.4)$ & 1 & 1 \\
\hline Pumping water & 19 (12.6) & $34(17.4)$ & $1.6(0.9-2.9)$ & $1.7(0.7-4.0)$ \\
\hline Protected well & $3(2)$ & $14(7.2)$ & $4.1(1.2-14.6)$ & $4.5(1.1-18.2)^{a}$ \\
\hline \multicolumn{5}{|l|}{ Availability of latrine } \\
\hline Yes & $128(84.8)$ & $156(80)$ & 1 & 1 \\
\hline No & $23(15.2)$ & $39(20)$ & $1.4(0.8-2.5)$ & $1.5(0.8-2.7)$ \\
\hline \multicolumn{5}{|l|}{ History of illness in the previous 2 weeks } \\
\hline Yes & $26(17.2)$ & $27(13.8)$ & $0.8(0.4-1.4)$ & $0.8(0.4-1.5)$ \\
\hline No & $125(82.8)$ & $168(86.2)$ & 1 & 1 \\
\hline \multicolumn{5}{|l|}{ Duration of menstruation (days) } \\
\hline$<4$ & $25(16.6)$ & $24(12.3)$ & 1 & 1 \\
\hline $4-6$ & $118(78.1)$ & $152(77.9)$ & $1.3(0.7-2.5)$ & $1.2(0.6-2.4)$ \\
\hline$>6$ & $8(5.3)$ & $19(9.7)$ & $2.4(0.9-6.7)$ & $2.4(0.8-6.9)$ \\
\hline \multicolumn{5}{|l|}{ Practicing home gardening } \\
\hline Yes & $23(15.2)$ & $18(9.2)$ & 1 & 1 \\
\hline No & $128(84.8)$ & $177(90.8)$ & $1.8(0.9-3.4)$ & $2.1(1.01-4.2)^{a}$ \\
\hline \multicolumn{5}{|l|}{ Daily eating pattern in the previous 7 days } \\
\hline Three meals and/or above & $68(45)$ & $68(34.9)$ & 1 & 1 \\
\hline Two meals \& eating between meals & $65(43)$ & $92(47.2)$ & $1.4(0.9-2.3)$ & $1.3(0.8-2.1)$ \\
\hline Two meals only or below & $18(11.9)$ & $35(17.9)$ & $1.9(1.01-3.8)$ & $1.8(0.9-3.7)$ \\
\hline
\end{tabular}

${ }^{\mathrm{a}} P$-value is significant at $<0.05, \mathrm{COR}=$ Crude Odds Ratio, $\mathrm{AOR}=$ Adjusted Odds Ratio, ETB = Ethiopian Birr

${ }^{\mathrm{b}}$ Adjusted for: educational status, occupation, residential address, average monthly income, availability of latrine, home gardening, history of illness in the previous 2 weeks, duration of menstruation (days), daily eating pattern in the previous 7 days and Source of drinking water 
between $501 \mathrm{ETB}$ and $1500 \mathrm{ETB}$, having two meals a day during previous 7 days, and having protected well source of drinking water were associated with low dietary diversity. In the multivariable level analysis; monthly income of less than 501 and 501 to 1500 ETB, not practicing home gardening, and protected well as main source of drinking water were predictors of low dietary diversity.

Lactating mothers who had monthly income less than 501 ETB and 501 to 1500 ETB were 2.3 and 3.0 times more likely to have low dietary diversity than those who had monthly income above 1500 ETB respectively $[[\mathrm{AOR}=2.3,95 \% \mathrm{CI}(1.2-4.6)]$ and $[\mathrm{AOR}=3.0,95 \% \mathrm{CI}$ (1.4-6.3)] respectively]. Among the lactating mothers, those who did not practice home gardening were 2.1 times more likely to have low dietary diversity than those who practice home gardening $[\mathrm{AOR}=2.1,95 \% \mathrm{CI}$ $(1.01,4.2)]$. Regarding source of drinking water, lactating mothers who reported protected well as a main source were 4.5 times more likely to have low dietary diversity than those who reported tap water as main source $[\mathrm{AOR}=4.5,95 \% \mathrm{CI}(1.1,18.2)]$.

\section{Discussion}

The study has assessed the dietary diversity among lactating mothers visiting public health facilities in Aksum town, Tigray region, Ethiopia. The mean DDS among the lactating women was 3.4 and $56 \%$ (95\% CI: 50.6, 61.6) of the women had DDS $<3.4$. This finding is lower than the finding of study conducted in three countries; Vietnam, Bangladesh, and Ethiopia, by Nguyen et al [26], in which dietary diversity was low in nearly three fourths of lactating mothers in Ethiopia. This might be explained by the difference in study period which can results in food security status change. In the previous study, more than two thirds of the study participants were food insecure. While in the present study, nearly a quarter was food insecure. There is also similar difference in educational status between study participants of both studies which could be another explanation for the observed discrepancy. Conversely, the finding of the present study is far higher than the prevalence of low dietary diversity among lactating mothers in the study from Vietnam, Bangladesh and Ethiopia [26]. This might be due to the difference in education, feeding culture and food security.

In this study, around 99.4 and $69.1 \%$ of the lactating mothers had consumed starchy staples, and legumes, nuts and seeds respectively in the previous $24 \mathrm{~h}$. Conversely, milk and milk products food group, and meat and fish food group were least consumed groups (12.4 and $17.1 \%$ respectively). This finding is almost consistent with the finding of other similar study conducted in Vietnam, Bangladesh and Ethiopia by Nguyen et al [26] and in Kenya by Ongosi et al [36].
Lactating mothers visiting public health facilities with a monthly income of 501-1500 ETB and $<501$ ETB were 3 and 2.3 times more likely to have low dietary diversity respectively, when compared to mothers who earned $>1500$ ETB per month. This study is in agreement with the study conducted in Bangladesh by Thorne-Lyman et al [32]. It has demonstrated that dietary diversity was significantly associated with the wealth status of the study participants; as the wealth index increased the likelihood of consuming diversified food have been observed to increase. A study in low and middle income countries also indicated that higher socio-economic status was associated with higher diet diversity score [33]. This could be due to the fact that low income earners recognized to be negatively affected on their preference of quality and quantity of diversified food groups consumed in their feeding arrangements attributable to income.

Home gardening practice of the study participants was found to be predictor of dietary diversity in this study. Lactating mothers who did not practice home gardening showed more than two folds higher likelihood of consuming low diversified diets when compared to mothers who practice home gardening. This study agreed with studies conducted in Philippines by Cabalda et al [34] and in Ethiopia by Tesema et al [35]. These studies have demonstrated that home gardening was strongly associated with diet diversity and with frequency of vegetable consumption. This might be due to the reason that households with gardens were beneficiary from gardens they own as a means to diversifying their daily food. It was also indicated that parents with home gardening would grow vegetables and get additional diet options that enhance the diversity of the household's food sources [35].

Furthermore, source of drinking water was found to be a determinant predictor of dietary diversity. Lactating mothers who reported protected well as a main source of drinking water were more likely to have low dietary diversity than those who reported tap water as main source. This might be partly explained by the difference in socioeconomic status as shown in a study conducted in three countries; Vietnam, Bangladesh, and Ethiopia, by Nguyen et al [26], in which household socioeconomic status (SES) was found to be positively associated with maternal dietary diversity.

Nevertheless of its marginality in the multivariate model, occupation of the study subjects has been associated with dietary diversity in the current study; lactating mothers who were unemployed during the study period had two folds higher likelihood of consuming poorly diversified food items when compared to those who owned private business. The possible explanation for this could be the purchasing power of lactating mothers is dictated by the presence and absence of occupation that they rely on as a source of income. 
Even if the proportion of food insecurity among the lactating mothers in this study was $27.2 \%$, it did not associate with dietary diversity. A study done in rural Cambodia and a study done in Rural Populations of Kilosa District, Tanzania indicated that there is no association between food security and dietary diversity $[36,37]$. However, a study done in older Taiwanese has indicated that there is significant association between food security and dietary diversity [38]. The difference in association of food security and dietary diversity among the study populations may be related with difference in educational level and socio economic status.

This study has some limitations. Although efforts were made to ensure representativeness of eligible women in the study area, no attempt was made to address seasonal variation which can affect food availability that can in turn influence dietary intake and diversity. Moreover, there is difficulty to measure food compositions and dishes due to diverse cultures and different ways of traditional food preparations. For example, injera (local name) is a food mostly consumed by the study participants. Injera can be prepared by composing different cereals which is differently composed in each household based on their economic ability to buy the different cereals.

\section{Conclusions}

The previous $24 \mathrm{~h}$ recall dietary diversity assessment indicated that mean DDS among the lactating mothers was 3.4. Among the lactating mothers, $56.4 \%$ had DDS less than 3.4. Factors like average monthly income less than 501 ETB and from 501 to 1500 ETB, not practicing home gardening, and protected well as main source of drinking water were strongly associated with low dietary diversity. Hence, additional programs and interventions should be designed and implemented conjointly with other health care services delivered in health facilities to address low dietary diversity among lactating mothers. Apart from this, nutritional education is essential in order to aware mothers on the importance of diversified diet consumption.

\section{Abbreviations \\ AOR, adjusted odds ratio; CEO, Chief Executive Officer; Cl, confidence interval; COR, crude odds ratio; DDS, Dietary Diversity Score; ETB, Ethiopian birr; FAO, \\ Food and Agriculture Organization; HFIAS, Household Food Insecurity Access Scale; IRB, Institutional Review Board; OR, odds ratio; SES, socioeconomic status; UNICEF, United Nations Children's Fund}

\section{Acknowledgements}

Aksum University Health Science College is acknowledged for supporting the study. We are also grateful for the hospital and health center administrations and the study participants for providing us the necessary information.

\section{Funding}

Aksum University Health Science College is funder of the study.
Availability of data and materials

All the required data supporting the findings are contained within the manuscript.

\section{Authors' contribution}

NB: conception, design, field study, data collection, analysis, interpretation, and writing of the manuscript. $\mathrm{KH}, \mathrm{MG}, \mathrm{BH}$ and $\mathrm{YS}$ : data analysis, interpretation and manuscript preparation. SW, HA, HG and WA: design, field study, data collection and analysis. All the authors read and approved the final manuscript to be submitted for publication.

\section{Competing interests}

The authors declare that they have no competing interests.

\section{Consent for publication}

Not applicable.

\section{Ethics approval and consent to participate}

Ethical clearance was obtained from Institutional Review Board (IRB) of Aksum University College of Health Sciences. Official letter written by the college IRB was submitted to Aksum health bureau and each selected health facilities with brief explanation about the purpose of the study. After getting permission from the Chief Executive Officer (CEO) and Medical Director of the facilities, verbal consent was secured from study participants to conduct the study before the interview. Anyone who was not willing to take part in the study was informed to do so. All information provided was kept confidential.

\section{Author details}

'Department of Public Health, College of Health Sciences, Aksum University, P. O. Box: 1010, Aksum, Ethiopia. ${ }^{2}$ Department of Midwifery, College of Health Sciences, Aksum University, Aksum, Ethiopia. ${ }^{3}$ Federal Ministry of Health, Addis Ababa, Ethiopia.

Received: 19 January 2016 Accepted: 25 June 2016

Published online: 07 July 2016

\section{References}

1. CORE Group. Maternal Nutrition during Pregnancy and Lactation [Internet]. 2004. Available from: www.coregroup.org

2. González-Cossío T, Habicht JP, Rasmussen KM, Delgado HL. Impact of food supplementation during lactation on infant breast-milk intake and on the proportion of infants exclusively breast-fed. J Nutr. 1998;128(10):1692-702.

3. Allen LH. B vitamins in breast milk: relative importance of maternal status and intake, and effects on infant status and function. Adv Nutr. 2012;3(3): 362-9.

4. Azizi F, Smyth P. Breastfeeding and maternal and infant iodine nutrition. Clin Endocrinol (Oxf). 2009:70(5):803-9.

5. Dawodu A, Tsang RC. Maternal vitamin D status: effect on milk vitamin D content and vitamin D status of breastfeeding infants. Adv Nutr. 2012;3(3): 353-61

6. Brown K, Dewey K. Relationships between maternal nutritional status and milk energy output of women in developing countries. In: Mechanisms regulating lactation and infant nutrient utilization. New York: Wiley-Liss; 1992. p. 77-95.

7. Dewey KG, Cohen RJ, Brown KH, Rivera LL. Effects of exclusive breastfeeding for four versus six months on maternal nutritional status and infant motor development: results of two randomized trials in Honduras. J Nutr. 2001;131(2):262-7.

8. Dewey KG. Energy and protein requirements during lactation. Annu Rev Nutr. 1997;17:19-36.

9. Jones KDJ, Berkley JA, Warner JO. Perinatal nutrition and immunity to infection. Pediatr Allergy Immunol. 2010;21(4 Pt 1):564-76.

10. Ministry of Health, ICF International. Ethiopian demographic and health survey 2011 report. Central Statistical Agency. https://dhsprogram.com/ pubs/pdf/FR255/FR255.pdf

11. UNICEF. Tracking Progress on child and maternal nutrition: A survival and development priority. 2009.

12. Maternal dietary diversity and the implications for children's diets in the context of food security | USAID's Infant \& Young Child Nutrition Project [Internet]. [cited 2015 Dec 5]. Available from: http://www.iycn.org/resource/ 
maternal-dietary-diversity-and-the-implications-for-children\%E2\%80\%99sdiets-in-the-context-of-food-security/

13. Mary A, Liv Elin T, Doris W, Maria J, Alicia C. Dietary Diversity as a Measure of Women's Diet Quality in Resource-Poor Areas: Results from Rural Bangladesh Site. Food and Nutrition Technical Assistance II Project (FANTA2); 2008. https://dhsprogram.com/pubs/pdf/FR255/FR255.pdf

14. Feed The Future. Feed the Future Handbook of Indicator Definitions [Internet]. Feed the Future. 2014 [cited 2015 Dec 26]. Available from: http:// feedthefuture.gov/resource/feed-future-handbook-indicator-definitions

15. Gina Kennedy, Terri Ballard, Marie Claude Dop. Guidelines for Measuring Household and Individual Dietary Diversity. Nutrition and Consumer Protection Division, Food and Agriculture Organization of the United Nations. https://dhsprogram.com/pubs/pdf/FR255/FR255.pdf

16. Arimond M, Wiesmann D, Becquey E, Carriquiry A, Daniels MC, Deitchler M, et al. Simple food group diversity indicators predict micronutrient adequacy of women's diets in 5 diverse, resource-poor settings. J Nutr. 2010;140(11): 2059S-69S.

17. Arimond M, Ruel MT. Dietary diversity is associated with child nutritional status: evidence from 11 demographic and health surveys. J Nutr. 2004; 134(10):2579-85

18. Henjum S, Torheim LE, Thorne-Lyman AL, Chandyo R, Fawzi WW, Shrestha PS, et al. Low dietary diversity and micronutrient adequacy among lactating women in a peri-urban area of Nepal. Public Health Nutr. 2015;18(17):3201-10.

19. Arsenault JE, Yakes EA, Islam MM, Hossain MB, Ahmed T, Hotz C, et al. Very low adequacy of micronutrient intakes by young children and women in rural Bangladesh is primarily explained by low food intake and limited diversity. J Nutr. 2013;143(2):197-203.

20. Hoddinott J, Yohannes Y. Dietary Diversity as a Household Food Security Indicator. USAID; 2002. https://dhsprogram.com/pubs/pdf/FR255/FR255.pdf

21. Ruel MT. Operationalizing dietary diversity: a review of measurement issues and research priorities. J Nutr. 2003;133(11 Suppl 2):3911S-26S.

22. PATH: Infant \& Young Child Nutrition Project [Internet]. [cited 2015 Dec 26]. Available from: http://www.path.org/projects/iycn.php

23. Becquey E, Martin-Prevel $Y$, Traissac $P$, Dembélé B, Bambara A, Delpeuch $F$. The household food insecurity access scale and an index-member dietary diversity score contribute valid and complementary information on household food insecurity in an urban West-African setting. J Nutr. 2010;140(12):2233-40.

24. $\mathrm{WHO} \mid$ Indicators for assessing infant and young child feeding practices [Internet]. [cited 2015 Dec 26]. Available from: http://www.who.int/ maternal_child_adolescent/documents/9789241596664/en/

25. Saaka M. Maternal dietary diversity and infant outcome of pregnant women in Northern Ghana. Int J Child Health Nutrition. 2013;1(2):148-56.

26. Nguyen PH, Avula R, Ruel MT, Saha KK, Ali D, Tran LM, et al. Maternal and child dietary diversity are associated in Bangladesh, Vietnam, and Ethiopia. J Nutr. 2013;143(7):1176-83.

27. Savy M, Martin-Prével Y, Traissac P, Eymard-Duvernay S, Delpeuch F. Dietary diversity scores and nutritional status of women change during the seasonal food shortage in rural Burkina Faso. J Nutr. 2006;136(10):2625-32.

28. Bhagowalia P, Headey DD, Kadiyala S. Agriculture, Income, and Nutrition Linkages in India: Insights from a Nationally Representative Survey: IFPRI discussion papers [Internet]. 2012 [cited 2015 Dec 26]; Available from: http://ideas.repec.org/p/fpr/ifprid/1195.html

29. Burchi F. Child nutrition in Mozambique in 2003: the role of mother's schooling and nutrition knowledge. Econ Hum Biol. 2010;8(3):331-45.

30. Zakaria H, Laribick DB. Socio-economic determinants of dietary diversity among women of child bearing ages in Northern Ghana. Food Sci Qual Manag. 2014;34:12-25.

31. FAO. Guidelines for measuring household and individual dietary diversity. 2013.

32. Ongosi AN, Gericke GJ, Mbuthia E, Oelofse A. Food variety, dietary diversity and perceived hunger among lactating women (0-6 months postpartum) in a low socio-economic area in Nairobi, Kenya. 2014 Apr [cited 2015 Dec 5]; Available from: http://repository.up.ac.za/handle/2263/45167

33. Maxwell D, Caldwell R, Langworthy M. Measuring food insecurity: Can an indicator based on localized coping behaviors be used to compare across contexts? Food Policy. 2008;33(6):533-40.

34. Frongillo EA, Nanama S. Development and validation of an experiencebased measure of household food insecurity within and across seasons in northern Burkina Faso. J Nutr. 2006;136(5):1409S-19S.
35. Knueppel D, Demment M, Kaiser L. Validation of the household food insecurity access scale in rural Tanzania. Public Health Nutr. 2010;13(03):360-7.

36. Ogechi UP. A Study of the nutritional status and dietary intake of lactating women in Umuahia, Nigeria. Am J Health Res. 2014;2(1):20.

37. Thorne-Lyman AL, Valpiani N, Sun K, Semba RD, Klotz CL, Kraemer K, et al. Household dietary diversity and food expenditures are closely linked in rural Bangladesh, increasing the risk of malnutrition due to the financial crisis. J Nutr. 2010;140(1):182S-8S.

38. Dietary Diversity as a Measure of Micronutrient Adequacy of Women's Diets in Resource-Poor Areas | Food and Nutrition Technical Assistance III Project (FANTA) [Internet]. [cited 2015 Dec 26]. Available from: http://www. fantaproject.org/research/womens-dietary-diversity-project

\section{Submit your next manuscript to BioMed Central and we will help you at every step:}

- We accept pre-submission inquiries

- Our selector tool helps you to find the most relevant journal

- We provide round the clock customer support

- Convenient online submission

- Thorough peer review

- Inclusion in PubMed and all major indexing services

- Maximum visibility for your research

Submit your manuscript at www.biomedcentral.com/submit
C Biomed Central 